\title{
PERUBAHAN KADAR AIR DAN SUHU TANAH AKIBAT PEMBERIAN MULSA ORGANIK PADA PERTANAMAN NANAS PT GREAT GIANT PINEAPPLE TERBANGGI BESAR LAMPUNG TENGAH
}

\author{
Meifma anetasia ${ }^{1}$, Afandi ${ }^{1}$, Hery Novpriansyah ${ }^{1}$, K.E.S. Manik ${ }^{1} \&$ Prio Cahyono $^{2}$ \\ ${ }^{1}$ Jurusan Agroteknologi, Fakultas Pertanian Universitas Lampung \\ Jl.Prof.Soemantri Brodjonegoro, No.1 Bandar Lampung 35145 \\ E-mail:meifimaanetasia@yahoo.co.id \\ ${ }^{2}$ Kepala Bagian Riset Agronomi PT Great Giant Pineapple \\ Jl. Raya arah Menggala KM 77 Kecamatan Terbanggi Besar, Kabupaten Lampung Tengah
}

\begin{abstract}
ABSTRAK
Nanas (Ananas comosus) membutuhkan air untuk pertumbuhannya yang maksimal. Salah satu upaya untuk mempertahankan kadar air dan suhu tanah saat musim kemarau yaitu dengan cara penambahan mulsa organik di atas permukaan tanah agar memperbaiki kondisi fisik tanah lapisan atas untuk menjaga temperatur (suhu), penguapan dan kadar air tanah, sehingga kadar air tanah dapat tersedia dan lebih hemat. Penelitian ini bertujuan untuk mengetahui pengaruh mulsa organik terhadap perubahan kadar air dan suhu tanah pada pertanaman nanas di PT Great Giant Pineapple Terbanggi besar Lampung Tengah. Penelitian ini disusun dalam rancangan acak lengkap (RAL), dengan perlakuan $\mathrm{M} 0=$ Tanpa mulsa, $\mathrm{M} 1=25 \mathrm{tha}^{-1} \cdot \mathrm{M} 2=50 \mathrm{tha}^{-1} \cdot \mathrm{M} 3=75 \mathrm{t}$ $\mathrm{ha}^{-1} \cdot \mathrm{M} 4=100 \mathrm{t} \mathrm{ha}^{-1}$. Mulsa organik yang digunakan pada penelitian ini adalah mulsa kulit singkong dengan kadar air 37,28\%, bibit nanas yang digunakan adalah bibit Sucker Klon GP3.Perlakuan M0 setelah hari ke-3 yaitu kadar air mencapai 20,83\% harus dilakukan irigasi. Sedangkan pada perlakuan M1 hari ke-3 kadar air mencapai 21,8 \% harus dilakukan proses irigasi. Perlakuan M2 setelah dilakukan pengamatan pada hari ke-7 dengan kadar air sebesar 21,18\%, sehingga harus dilakukan proses irigasi. Perlakuan M3 setelah dilakukan pengamatan pada hari ke-10 yaitu dengan kadar air tanah mencapai 22,4\%, sehingga harus dilakukan proses irigasi, sedangkan M4 pada hari ke-10 kadar air menjadi 22,56 \%, sehingga sudah harus dilakukan proses irigasi. Maka, penelitian ini yang mampu bertahan lebih lama dalam memenuhi kebutuhan air pada perlakuan M3 dan M4 yaitu dapat bertahan selama 10 hari.
\end{abstract}

Kata Kunci : nanas, mulsa organik, kadar air, suhu tanah

\section{PENDAHULUAN}

Air merupakan faktor yang sangat penting untuk keberhasilan budidaya tanaman. Tumbuhan dapat tumbuh subur dan berkembang dengan baik dipengaruhi oleh ketersediaan air. Tumbuhan membutuhkan air untuk memenuhi kebutuhan fisiologisnya. Air yang dibutuhkan oleh tumbuhan dapat berasal dari alam berupa air hujan dan air tanah. Tetapi seringkali tumbuhan mengalami kekurangan air karena kurangnya air tersedia disekitar tumbuhan tersebut, sehingga diperlukan suatu penambahan air (Antoni, 2009).

Pada saat musim kemarau tanaman membutuhkan aplikasi irigasi intensif, namun pemberian air irigasi secara tepat waktu dan efisien juga berpengaruh terhadap besarnya biaya yang dikontribusikan, sehingga manajemen irigasi perlu dikelola secara baik.

Salah satu cara untuk mengatasi kekeringan adalah dengan cara pemberian mulsa, karena mulsa dapat menghambat laju evaporasi, terkendalinya laju evapotranspirasi diharapkan dapat menjaga lengas tanah atau kadar air tanah sehingga dapat mendukung pertumbuhan tanaman, serta memperbaiki kondisi fisik dan kimia tanah (Anwarudinsyah et al., 1993; Rizal dan Hariastuti, 2001, dalam Mawardi et al., 2004).

Komariah et al.,(2008), mengatakan bahwa aplikasi mulsa pada permukaan tanah memberikan peluang untuk memanfaatkan berbagai limbah bahan organik tanaman yang banyak manfaat, terutama hubungannya dengan tanah dan air. Kemampuan mulsa dalam meminimalkan avaporasi juga membantu untuk menjaga suhu tanah. Mulsa organik dapat bertindak sebagai bahan isolasi untuk lapisan tanah, karena dapat menurunkan suhu tanah pada saat suhu udara tinggi dan menghangatkan tanah selama suhu udara rendah.

Mulsa adalah komponen penting dalam sistem pertanian berkelanjutan. Pada awal sejarahnya, sistem mulsa banyak digunakan petani untuk mengurangi gulma yang tumbuh di antara baris jalur pertanaman. Cara ini kini banyak diterapkan di sistem pertanaman. Mulsa organik adalah sisa tanaman yang disebar di permukaan tanah. Mulsa berguna untuk melindungi permukaan 
tanah dari terpaan hujan, erosi, menjaga kelembaban, struktur, dan kesuburan tanah (Gillespie et al., 1992).

Dari hasil penelitian Mawardi et al., (2004), menyatakan pemberian mulsa saat musim kemarau dapat mempertahankan kadar air tanah dan suhu tanah. Semakin tinggi dosis mulsa yang diaplikasikan ke permukaan tanah maka kelembaban tanah dan suhu tanah dapat dipertahankan keadaannya. Perlakuan pemulsaan memiliki kelembaban tanah yang meningkat seiring dengan bertambahnya dosis pemulsaan dari 4, 8 dan $12 \mathrm{t} \mathrm{ha}_{-}^{-1}$. Perlakuan pemulsaaan 12 ton ha ${ }^{-1}$ memiliki kelembaban tanah lebih tinggi.

Penelitian ini bertujuan untuk mengetahui pengaruh mulsa organik terhadap perubahan kadar air dan suhu tanah pada pertanaman nanas di PT Great Giant Pineapple (PT GGP) Terbanggi besar Lampung Tengah.

\section{BAHAN DAN METODE}

Penelitian ini dilaksanakan pada bulan September sampai dengan Oktober 2012 pada lahan pertanaman Nanas di PT GGP Terbanggi Besar, Lampung Tengah. Analisis suhu tanah dilakukan di lahan pertanaman nanas PT GGP. Analisis kadar air volumetri dilakukan di Laboratorium PT GGP Terbanggi Besar Lampung Tengah. Metode yang digunakan untuk petak rancangan percobaan dalam penelitian ini adalah metode Rancangan Acak Lengkap (RAL) dengan 4 ulangan, total seluruh percobaan adalah 20 satuan percobaan. Masing-masing perlakuan yang diberikan adalah :

1. Mo (Tanpa mulsa kulit singkong)

2. M1 (Mulsa kulit singkong $25 \mathrm{t} \mathrm{ha}^{-1}$ )

3. M2 (Mulsa kulit singkong $50 \mathrm{t} \mathrm{ha}^{-1}$ )

4. M3 (Mulsa kulit singkong $75 \mathrm{t} \mathrm{ha}^{-1}$ )

5. M4 (Mulsa kulit singkong $100 \mathrm{t} \mathrm{ha}^{-1}$ )

Data hasil pengamatan dianalisis menggunakan metode Time Series. Sedangkan pengamatan pada hari ke-10 dan hari terahir dilakukan analisis statistik menggunakan metode Rancangan Acak Lengkap (RAL).

Penelitian ini dilakukan pada lahan Nanas PT GGP. Persiapan lahan meliputi kegiatan pengolahan tanah dan pembuatan petak satuan percobaan. Pengolahan tanah dilakukan dengan pembajakan menggunakan traktor, sehingga tanah menjadi gembur. Setelah itu tanah diratakan menggunakan rotary. Lahan dibagi menjadi 20 petak percobaan sesuai dengan perlakuan, dan ukuran tiap petaknya $3,5 \mathrm{~m} \times 2,5 \mathrm{~m}$ dengan jarak antar petak yaitu $0,5 \mathrm{~m}$.

Tanaman nanas yang sudah berumur \pm 1 bulan, dipindahkan ke lahan yang sudah diolah. Setelah itu aplikasikan mulsa organik pada lahan dengan cara ditabur secara merata sesuai dengan perlakuan dan petak percobaan yang telah dibuat.

Peubah yang diamati adalah kadar air dan suhu tanah. Pengamatan kadar air dilakukan setiap hari selama 3 minggu. Pengukuran suhu dilakukan 2 kali sehari yaitu pagi dan siang hari setiap kali pengamatan selama 3 minggu. Alat yang digunakan untuk mengukur suhu tanah yaitu Soiltech.

\section{HASIL DAN PEMBAHASAN}

Data kadar air tanah pada pertanaman nanas akibat pemberian mulsa disajikan pada Gambar.1. Dari Gambar 1 terlihat bahwa kadar air tanah semakin menurun tiap waktu, penurunan kadar air tanah yang diberi mulsa lebih rendah daripada tanah yang tidak diberi mulsa. Penurunan kadar air terendah terdapat pada perlakuan pemberian mulsa $100 \mathrm{t} \mathrm{ha}^{-1}$, kemudian berturut- turut 75,50 , dan $25 \mathrm{t} \mathrm{ha}^{-1}$.

Penurunan kadar air per-hari pada setiap perlakuan berbeda. Semakin banyak mulsa yang diaplikasikan maka penurunan kadar air akan semakin rendah, namun sebaliknya jika semakin sedikit mulsa yang diaplikasikan maka penurunan kadar air semakin tinggi. Pada penelitian ini pada perlakuan Mo (tanpa mulsa) menunjukan penurunan kadar air yang paling tinggi, selanjutnya berturut- turut pada perlakuan 25,50 , dan $100 \mathrm{t} \mathrm{ha}^{-1}$. Data selengkapnya dapat dilihat pada Gambar 2.

Uji BNT Pengaruh mulsa organik terhadap kadar air tanah hari ke-10 setelah diaplikasikan mulsa kulit singkong setiap perlakuan memiliki nilai kadar air yang berbeda-beda yaitu pada perlakuan M4 kadar air tanah setelah ditransformasi sebesar 4,6550, perlakuan M3 setelah ditransformasi sebesar 4,6075 , perlakuan M2 setelah ditransformasi yaitu 4,3500 , perlakuan M1 setelah ditransformasi yaitu 3,8875 , sedangkan pada perlakuan M0 setelah ditransformasi yaitu 3,4775. Dengan nilai BNT pada taraf 5\% yaitu sebesar 0,27.

Uji BNT pada hari ke-18 pengamatan kadar air tanah setelah diaplikasikan mulsa kulit singkong, menunjukan bahwa perlakuan M4 dan M3 tidak berpengaruh nyata, yaitu pada perlakuan M4 data setelah ditransformasi mencapai 4.0450, sedangkan pada M3 setelah ditransformasi mencapai 3.9500, dengan nilai BNT pada taraf 5\% sebesar 0.22.

Data Suhu tanah di pertanaman nanas setelah di aplikasikan mulsa organik disajikan pada grafik.3. Semakin banyak mulsa yang diberikan ketanah maka suhu akan semakin rendah, namun sebaliknya jika mulsa yang diberikan ketanah semakin sedikit maka suhu tanah akan lebih tinggi. Suhu terendah terdapat pada perlakuan 


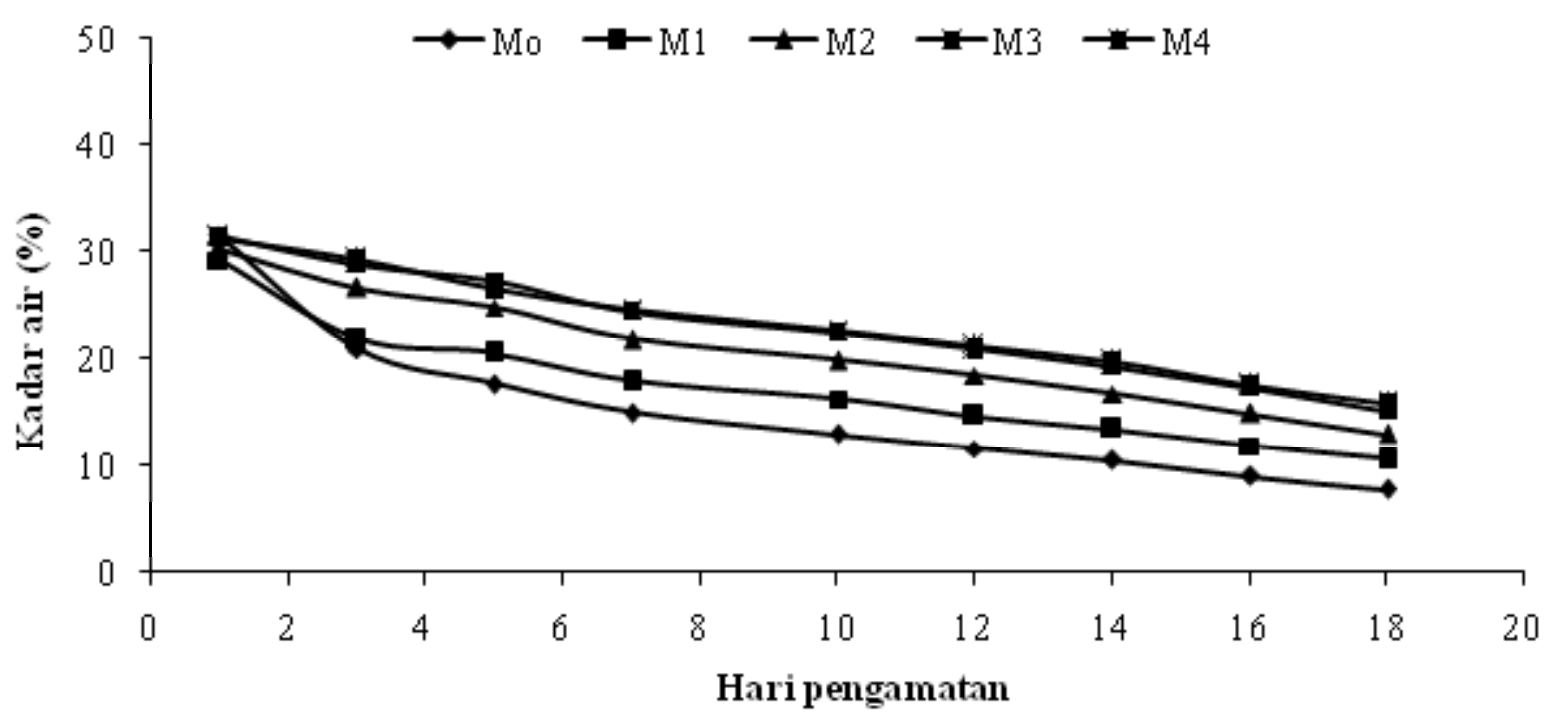

Gambar 1. Kadar air tanah setelah aplikasi mulsa organik. M0 $=$ Tanpa mulsa, M1 $=25 \mathrm{t} \mathrm{ha}^{-1}, \mathrm{M} 2=50 \mathrm{t} \mathrm{ha}^{-1}$, $\mathrm{M} 3=75 \mathrm{tha}^{-1}, \mathrm{M} 4=100 \mathrm{tha}^{-1}$.

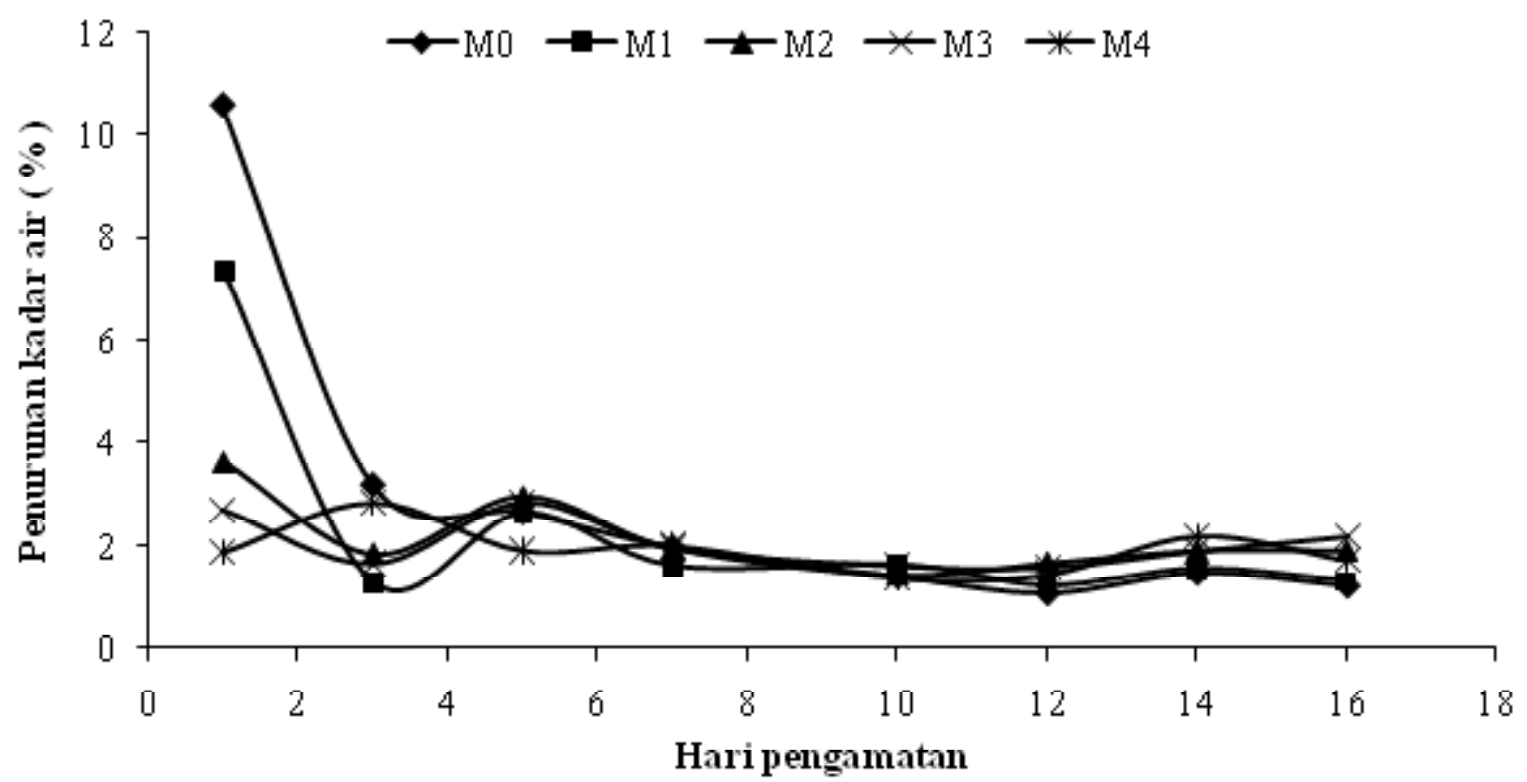

Gambar 2. Penurunan kadar air tanah perhari (water depletion). $\mathrm{M} 0=$ Tanpa mulsa, $\mathrm{M} 1=25 \mathrm{tha}^{-1}, \mathrm{M} 2=50 \mathrm{tha}^{-1}$, $\mathrm{M} 3=75 \mathrm{t} \mathrm{ha}^{-1}, \mathrm{M} 4=100 \mathrm{tha}^{-1}$.

pemberian mulsa yaitu pada perlakuan $100 \mathrm{t} \mathrm{ha}^{-1}$, selanjutnya pada perlakuan 75,50 , dan $25 \mathrm{t} \mathrm{ha}^{-1}$. Sedangkan pada perlakuan Mo (tanpa mulsa) suhunya paling tinggi dibandingkan dengan perlakuan yang lain. Data selengkapnya dapat dilihat pada Gambar 3.

Uji BNT terhadap suhu tanah hari ke-10 setelah diaplikasikan mulsa kulit singkong pada perlakuan M3 dan M4 merupakan perlakuan yang tidak berpengaruh nyata yaitu pada perlakuan M3 diperoleh data setelah ditransformasi 5.9575, sedangkan pada perlakuan M4 data setelah ditransformasi 5.9150 dengan nilai BNT pada taraf $5 \%$ sebesar 0.08 .

Uji BNT terhadap Suhu Tanah pada hari ke-16 setelah diaplikasikan mulsa kulit singkong pada perlakuan M2 dan M3 merupakan perlakuan yang tidak berpengaruh nyata, diperoleh data pada perlakuan M2 setelah ditransformasi yaitu sebesar 6.2400, sedangkan pada perlakuan M3 setelah ditransformasi yaitu sebesar 6,2400 nilai BNT padataraf $5 \%$ yaitu 0.08 . 
Dari hasil pengamatan dapat dijelaskan bahwa kadar air tanah dengan pemberian mulsa kulit singkong relatif dapat mengendalikan hilangnya air dari dalam tanah dibanding dengan tanah tanpa mulsa (MO). Oleh karena itu penggunaan mulsa merupakan hal yang perlu diperhatikan, karena dapat mengendalikan hilangnya air dari dalam tanah.

Penurunan kadar air (water depletion) sangat tinggi pada perlakuan Mo, disebabkan uap air dari dalam tanah yang menguap tidak diberikan mulsa organik, sedangkan pada perlakuan M1, M2, M3, M4, semakin banyak mulsa yang diaplikasikan tingkat penurunan kadar air semakin rendah. Selain itu dapat dilihat pada grafik 1 pada awal pengamatan penurunan kadar air masih tinggi belum stabil dikarenakan pada saat awal irigasi unsur pori makro yang bekerja, sedangkan pada saat pengamatan hari ke-10 setelah siram, penguapan kadar air lebih stabil dikarenakan penguapan yang berasal dari pori makro sudah habis sehingga yang bekerja dalam penguapan kadar air selanjutnya adalah pori mikro.

Sudaryono (2005), menyatakan lengas tanah adalah air yang terikat didalam pori tanah bersama-sama dengan garam yang larut di dalamnya membentuk larutan tanah yang penting sebagai perantara untuk memberikan unsur- unsur hara tanah, pembentukan tanah dan pertumbuhan tanaman. Lengas tanah membantu menjaga suhu tanah agar tidak terlalu panas maupun terlalu dingin.

Dalam penelitian ini semua perlakuan diberikan air yang sama, dapat dilihat pada Gambar 2 diatas yang mengalami penuruan kada air (water depletion) yang rendah terjadi pada perlakuan M3 dan M4, pada hari pertama pengamatan setelah diaplikasikan mulsa organik yaitu pada M3 sebesar 2,68\%, Sedangkan pada perlakuan M4 pada hari pertama pengamatan yaitu $1,86 \%$. Penurunan kadar air (water depletion) yang tinggi terjadi pada perlakuan M0, yaitu pada hari pertama pengamatan lengas tanah $10,57 \%$. Water depletion mulai stabil pada pengamatan hari ke-10 yaitu rata-rata berkisar antara 1,5-2,0\% (dapat dilihat pada Grafik.2)

Apabila suhu tanah naik akan berakibat berkurangnya kandungan air dalam tanah, sebaliknya jika suhu tanah rendah maka akan semakin bertambah nya kandungan air dalam tanah. Berdasarkan hasil pengamatan pada Gambar 3 di atas suhu tertinggi ada pada perlakuan tanpa mulsa (MO) yaitu pada hari ke10 sebesar $41^{\circ} \mathrm{C}$, disebabkan karena tidak diberi mulsa organik, sehingga suhu tanah sangat tinggi. Sedangkan pada suhu terendah ialah pada perlakuan $100 \mathrm{t} \mathrm{ha}^{-1}$ yaitu sebesar $38^{\circ} \mathrm{c}$ pada hari ke-10, disebabkan tanah tertutup oleh mulsa kulit singkong sehingga banyak suhu yang digunakan untuk melakukan respirasi.

Menurut Mahmood et al.,(2002) dalam Ridha, (2012), penurunan suhu tanah oleh mulsa disebabkan karena penggunaan mulsa dapat mengurangi radiasi yang diterima dan diserap oleh tanah sehingga dapat menurunkan suhu tanah pada siang hari. Ridha, (2012) menyatakan, dengan menurunkan suhu tanah dapat menekan kehilangan air dari permukaan tanah. sehingga mengurangi adanya cekaman kekeringan.

Setelah dilakukan analisis laboratorium lokasi $36 \mathrm{H}$ memiliki tekstur berjenis tanah liat (clay). Berdasarkan data yang diperoleh oleh pihak PT GGP lokasi 36 PG1, bahwa kadar air dengan kapasitas lapang maksimal $41 \%$, dan minimal 34\% maka dengan keadaan kadar air tanah mencapai $23 \%$ sudah harus di lakukan proses irigasi.

Berdasarkan data yang diperoleh kadar air dengan kapasitas lapang mencapai $31 \%$, maka titik layu nya yaitu $15 \%$, sehingga air tersedia sebesar $16 \%$,oleh karena itu dengan keadaan kadar air mencapai 23\% sudah harus dilakukan proses irigasi. Kadar air awal setelah siram untuk perlakuan M0 yaitu 31,4\%, maka diperoleh data setelah hari ke-3 yaitu kadar air pada M0 mencapai $20,83 \%$ harus dilakukan irigasi. Sedangkan pada perlakuan M1 yaitu kadar air awal setelah siram mencapai $29,18 \%$, pada hari ke-3 kadar air mencapai $21,8 \%$ harus dilakukan proses irigasi. Perlakuan M2 kadar air setelah siram pada hari ke-1 pengamatan mencapai $30,22 \%$, setelah dilakukan pengamatan pada hari ke-7 dengan kadar air sebesar $21,18 \%$, sehingga harus dilakukan proses irigasi.

Perlakuan M3 kadar air hari ke-1 pengamatan mencapai $31,49 \%$, setelah dilakukan pengamatan pada hari ke-10 yaitu dengan kadar air tanah mencapai $22,4 \%$, sehingga harus dilakukan proses irigasi, sedangkan M4 kadar air hari ke-1 yaitu 31,13\% pada hari ke-10 kadar air menjadi $22,56 \%$, sehingga sudah harus dilakukan proses irigasi.

Berdasarkan data yang telah diamati, pada masing- masing perlakuan yaitu M0, M1, M2, M3, dan M4. Maka, penelitian ini yang mampu bertahan lebih lama dalam memenuhi kebutuhan air pada perlakuan M3 dan M4 yaitu dapat bertahan selama 10 hari. Dapat dilihat pada Tabel 1 bahwa M3 dan M4 tidak menunjukan perberbedaan nyata, oleh karena itu dengan perlakuan M3 saja sudah cukup memenuhi kebutuhan air untuk pertumbuhan tanaman nanas kecil, sehingga tidak perlu sampai dengan perlakuan M4. 
Tabel 1. Uji BNT pengaruh mulsa organik terhadap kadar air tanah hari ke-10 setelah diaplikasikan mulsa kulit singkong

\begin{tabular}{cc}
\hline Perlakuan & Kadar air (\%) \\
\hline M4 & $4,62 \mathrm{a}$ \\
M3 & $4,61 \mathrm{ab}$ \\
M2 & $4,35 \mathrm{~b}$ \\
M1 & $3,89 \mathrm{c}$ \\
M0 & $3,48 \mathrm{~d}$ \\
\hline BNT & 0,27 \\
\hline
\end{tabular}

Keterangan: $\mathrm{M} 0=$ Tanpa mulsa, $\mathrm{M} 1=25 \mathrm{t} \mathrm{ha}^{-1} \mathrm{M} 2=50 \mathrm{t} \mathrm{ha}^{-1} \cdot \mathrm{M} 3=75 \mathrm{t} \mathrm{ha}^{-1} \cdot \mathrm{M} 4=100 \mathrm{t} \mathrm{ha}^{-1}$. Angka dalam tanda kurung adalah hasil transformasi. Angka-angka yang diikuti huruf yang sama pada kolomyang sama tidak berpengaruh nyata berdasarkan uji BNT pada $\alpha_{0,05}$.

\section{KESIMPULAN}

Berdasarkan hasil penelitan dapat diambil kesimpulan bahwa pengaplikasian mulsa kulit singkong mengakibatkan kadar air tanahnya tinggi dan suhu tanahnya rendah, sedangkan tanah yang tidak diberikan mulsa kulit singkong kadar air tanahnya rendah dan suhu tanahnya tinggi. Pengaplikasian mulsa kulit singkong berdosis $100 \mathrm{t} \mathrm{h}^{-1}$ (M4) kadar air tanahnya tinggi dan suhu tanahnya rendah, sedangkan mulsa kulit singkong berdosis $0 \mathrm{th}^{-1}, 25 \mathrm{th}^{-1}, 50 \mathrm{th}^{-1}$ dan $75 \mathrm{th}^{-1}$ mengakibatkan kadar air tanahnya rendah dan suhu tanahnya tinggi.

\section{SANWACANA}

Ucapan terima kasih kepada PT GGP atas kesempatan untuk dapat melaksanakan penelitian ini dan informasi data yang diperlukan dalam penelitian ini.

\section{DAFTAR PUSTAKA}

Bartholomew, D.P., R.E. Paull, dan K.G.. Rohrbach. 2003. The Pinapple. Jurnal University of Hawaii at Manoa Honolulu USA. Hal : 102-105.
Gillespie, T.J., C.J. Swanton, and .C.S. Wagner. 1992. The Effect of Organic Mulches on Soil Moisture and Crop Growt. Jurnal of Technology Evaluation And Development:56-58.

Hakim, N., M.Y. Nyakpa, A.M. Lubis, S.G. Nugroho, M.A. Diha, G.B. Hong, dan H.H. Bailey. 1986. Dasar-dasar Ilmu Tanah. Penerbit Universitas Lampung: Lampung. Hal:50-53.

Komariah, I. Kengo, S. Masateru, T.A. John, dan Afandi. 2008.The influences of organik munches on soil moisture content and temperature. Jurnal of rainwater catchment system 14(1):1-8.

Mulumba, L.N., and L. Rattan. 2008. Mulching effects on selected soil physical properties. Jurnal of Soil \& Tillage Research 98 (2008) 106-111

Williams, D.J. 1997. Organic Mulch. Jurnal of Cooperative Extension Service University of Illinois at Urbana-Champaign College of Agricultural, Consumer and EnvironmentalScienc. Hal : 110-113. 
